\title{
Edukasi Pencegahan dan Deteksi Dini Komorbid TB- DM pada Kader TB-HIV Care 'Aisyiyah
}

\author{
Merita Arini, 1* Fitria Nurul Hidayah² \\ 1Departemen Ilmu Kedokteran Keluarga dan Kesehatan Masyarakat, Prgram Studi Pendidikan Sarjana Kedokteran, Fakultas Kedokteran dan \\ Ilmu Kesehatan, Universitas Muhammadiyah Yogyakarta \\ 2Departemen Ilmu Penyakit Dalam, Prgram Studi Pendidikan Sarjana Kedokteran, Fakultas Kedokteran dan Ilmu Kesehatan, Universitas \\ Muhammadiyah Yogyakarta \\ Kampus Terpadu UMY, Jl. Brawijaya, Geblagan, Tamantirto, Kec. Kasihan, Bantul, Daerah Istimewa Yogyakarta 55183 \\ Email: merita.arini@umy.ac.id \\ DOI: $10.18196 / p p m \cdot 32.179$
}

\begin{abstract}
Abstrak
Tuberculosis (TB) dan Diabetes Mellitus (DM) merupakan kondisi komorbid kronis yang mengalami lonjakan ko-epidemik. Di sisi lain, keterlibatan komunitas umumnya belum dimulai. Tujuan pengabdian masyarakat kali ini adalah untuk meningkatkan pengetahuan kader tentang TB-DM dan meningkatkan kesinambungan program kesehatan dengan melakukan engagement dengan fasilitas kesehatan setempat. Mitra pengabdian masyarakat adalah kader TB-HIV Care Aisyiyah Kota Yogyakarta. Kegiatan dilakukan dengan satu siklus action research, meliputi: 1) diagnosing/ assessment kebutuhan komunitas sasaran, 2) planning/ perencanaan kegiatan, 3) action berupa implementasi sesi edukasi tentang komorbiditas TB-DM serta pelibatan petugas kesehatan setempat sebagai health educator, 4) evaluation/ analisis peningkatan skor pengetahuan kader dan refleksi. Materi edukasi diberikan dalam dua sesi ceramah dan ditambah dengan media edukasi yang telah diujicobakan pada kelompok lainnya. Wilcoxon Sign Rank Test digunakan untuk menganalisis perbedaan skor pre-test dan post-test dalam intervensi/ quasi experiment tanpa kelompok kontrol. Hasilnya didapatkan peningkatan signifikan rata-rata skor total pengetahuan kader tentang komorbiditas TB-DM ( $p=0.001)$. Media dan upaya edukasi dinyatakan acceptable dan feasible digunakan pada karakteristik pengguna kader. Kegiatan edukasi bermanfaat meningkatkan pengetahuan kader tentang TB-DM. Kader berpotensi meningkatkan upaya promosi pencegahan dan deteksi dini TB-DM di masyarakat.
\end{abstract}

Kata kunci: promosi kesehatan, deteksi dini penyakit, penyakit kronis

\section{Pendahuluan}

TB dan DM merupakan 2 dari 10 besar penyakit yang menyebabkan kematian terbanyak di dunia (World Health Organization, 2019). Adapun komorbid TB dan DM sendiri memiliki prevalensi sekitar 10-30 \% pada penderita TB/ DM (WHO, 2018). Prevalensi TB dan DM cukup besar di Indonesia. Badan Penelitian dan Pengembangan Kesehatan memublikasikan hasil survei TB-DM di 7 rumah sakit, yakni ada 740 kasus TB dan 110 penyandang DM (14,9\%) (Kemenkes RI, 2015). Hal ini mengonfirmasi tingginya prevalensi TB pada pasien DM sekaligus potensi penemuan kasus keduanya secara bi-directional. Provinsi Dairah Istimewa Yogyakarta (DIY) masih menduduki peringkat tiga besar nasional prevalensi DM (Kemenkes RI, 2018). Oleh karena itu, risiko berkembangnya TB pada penderita DM menjadi makin besar di provinsi ini.

Dalam Keputusan Menteri Indonesia Republik Indonesia Nomor HK.01.07/MENKES/755/2019 tentang Pedoman Nasional Pelayanan Kedokteran Tata Laksana Tuberkulosis (2019), ditegaskan bahwa pengelolaan TB-DM harus difokuskan pada diagnosis sedini mungkin, pengendalian glukosa, serta monitoring klinis dan pengobatan ketat. Namun demikian, ditemukan beberapa masalah programmatik pada implementasi kolaborasi TB-DM. Dalam hal teknis screening TB dan DM pada setting pelayanan rutin masih terdapat kontroversi. Inovasi upaya potensial yang direkomendasikan adalah peningkatan screening dan penegakkan diagnosis dini, seperti edukasi pasien dan keluarga. Hal ini merupakan metode yang paling sederhana dan murah serta belum banyak diteliti (Harries et al., 2015). Hal-hal tersebut di atas sangat mendesak untuk diupayakan mengingat Indonesia menargetkan zero TB pada tahun 2035 . 
Kota Yogyakarta memiliki delapan belas puskesmas yang menjadi unit pelaksana teknis Dinas Kesehatan Kota Yogyakarta. Adapun TB-HIV Care Aisyiyah merupakan organisasi kader pendukung yang telah aktif membantu puskesmas dan Dinas Kesehatan dalam program pengendalian TB dan HIV secara komprehensif. Berdasarkan latar belakang masalah yang telah dijelaskan di atas, rumusan masalah dalam pengabdian masyarakat ini adalah belum adanya program yang melibatkan peran komunitas sebagai salah satu komponen pengendalian dan pelayanan TB-DM yang berkesinambungan. Oleh karena itu, diperlukan upaya pemberdayaan kader untuk mendorong peningkatan penemuan kasus dan keberhasilan pengobatan yang dapat dijalankan secara berkesinambungan. Tujuan pengabdian masyarakat ini ialah untuk meningkatkan pengetahuan kader tentang TB-DM serta meningkatkan kesinambungan program dengan engagement dengan fasilitas kesehatan setempat.

\section{Metode Pelaksanaan}

Kegatan pengabdian masyarakat dilakukan dalam tahapan action researchs $(A R)$ dalam satu siklus (Coghlan \& Brannick, 2005). AR yang dilakukan menggunakan pendekatan partisipasi dan keterlibatan mitra consultation. Dalam hal ini, pengabdi meminta pendapat mitra, tetapi analisis dan tindakan ditetapkan oleh pengabdi (Utarini, 2020). Metode ini dipilih dengan tujuan meningkatkan keterlibatan dan kapasitas mitra dalam mengidentifikasi masalah mereka dan melakukan pemencahannya. Adapun empat tahap AR yang dilakukan adalah sebagai berikut.

1. Diagnosis

Tujuan tahap ini untuk mengidentifikasi kebutuhan kader. Pada tahap ini dilakukan wawancara dengan pengurus dan dokter di puskesmas wilayah Kota Yogyakarta secara daring karena pandemi Covid-19. Selain itu, pengabdi juga mengidentifikasi masalah yang ada melalui diskusi intensif dengan Dinas Kesehatan Kota Yogyakarta selama periode pelaksanaan kegiatan.

2. Planning

Tujuan tahap ini adalah menyusun dan menyepakati upaya edukasi yang dimungkinkan acceptable dan efektif bagi para kader yang pada umumnya telah berusia lanjut. Koordinasi dilakukan oleh pengabdi dengan pengurus dan puskesmas setempat secara daring.

3. Action

Tahap ini bertujuan untuk menerapkan perencanaan yang telah disusun sebelumnya, yaitu dengan melakukan intervensi secara kuasi eksperimen tanpa kelompok kontrol. Intervensi dilakukan berupa pelatihan kepada kader dengan pengabdi dan petugas puskesmas terlatih sebagai pemateri. Total sampel dilakukan pada seluruh kader TB-HIV Care 'Aisyiyah Kota Yogyakarta. Kegiatan meliputi

a. Pengisian kuesioner (pre-test dan post-test). Pertanyaan yang diberikan terbagi dalam empat domain (faktor risiko TB, gejala TB-DM, bahaya TB-DM, peran kader).

b. Edukasi kader oleh pengabdi dan petugas kesehatan puskesmas terlatih.

c. Distribusi media edukasi TB-DM berupa leaflet dan penayangan video edukasi.

Upaya edukasi dilakukan secara luring dengan tetap menerapkan protokol kesehatan sejak peserta datang hingga pulang kembali.

4. Evaluasi, untuk menilai

a. Analisis Statistik

Analisis deskriptif, uji normalitas (uji Komolgorov-Smirnof dan Saphiro-Wilk), serta uji beda mean tidak berpasangan (Wilcoxon's Signed Rank-Test) dilakukan terhadap pengetahuan kader tentang TB-DM (skor pre-dan post-test).

b. Feedback tentang kegiatan

Wawancara dan observasi situasi pelaksanaan kegiatan edukasi dilakukan untuk menilai pendapat mitra kader, pengurus, dan puskesmas tetang pelaksanaan dan manfaat kegiatan. Analisis secara naratif dilakukan terhadap data kualitatif yang 
didapatkan.

\section{Hasil dan Pembahasan \\ Hasil}

Berdasarkan identifikasi masalah dalam tahap diagnosis, didapatkan informasi bahwa para kader sebenarnya sudah mulai diedukasi mengenai DM yang merupakan salah satu faktor risiko TB. Namun demikian, belum pernah ada materi spesifik mengenai TB-DM yang meliputi pencegahan, identifikasi kasus, serta pengelolaannya. Demikian pula, kader belum pernah diberikan informasi mengenai program terkini pemerintah yang dijalankan, khsusnya di puskesmas. Oleh karena itu, perencanaan materi dan kegiatan edukasi kemudian disusun berdasarkan kebutuhan kader. Dalam pelaksanaan sesi edukasi, terdapat 32 kader yang hadir dari 35 peserta yang diundang.
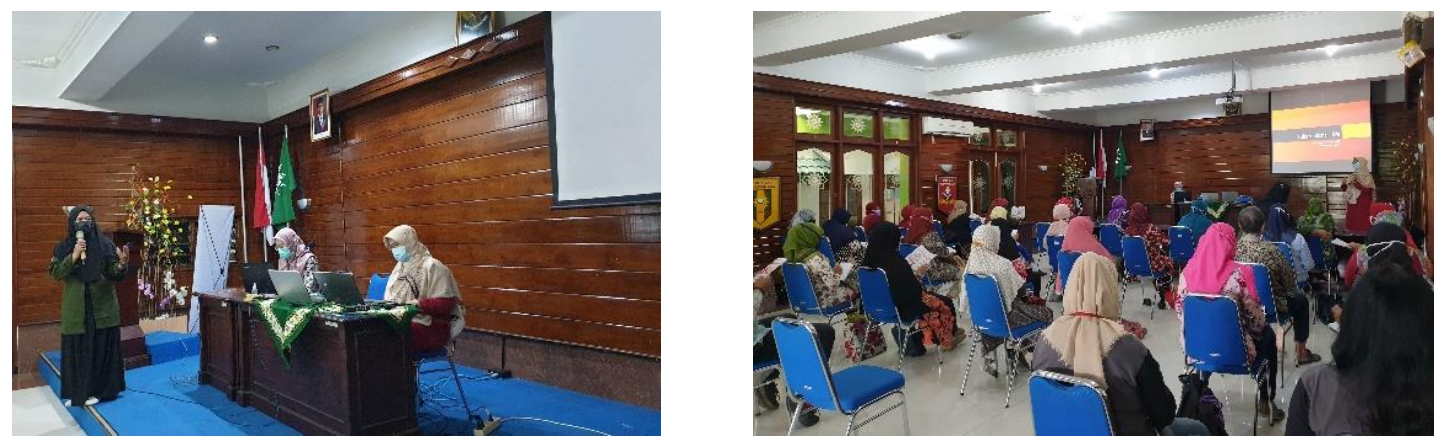

Gambar 1. Sesi Edukasi TB-DM pada Kader TB Care ‘Aisyiyah

Di awal dan di akhir kegiatan, peserta mengisi kuesioner pre-test dan post-test untuk menilai pengetahuan mereka tentang TB-DM. Respon rate responden adalah $100 \%$ dan seluruh responden mengembalikan kuesioner dengan lengkap. Tabel 2 dan 3 menampilkan data demografi responden.

\section{Tabel 2. Karakteristik Responden (Kader TB Care 'Aisyiyah)}

\begin{tabular}{lll}
\hline \multicolumn{1}{c}{ Karakteristik } & \multicolumn{1}{c}{$\mathbf{n}$} & \multicolumn{1}{c}{$\%$} \\
\hline Jenis Kelamin & & \\
Laki-laki & 4 & 12.5 \\
Perempuan & 28 & 87.5 \\
\hline Usia (tahun) & & \\
$21-30$ & 1 & 3.1 \\
$31-40$ & 1 & 3.1 \\
$41-50$ & 9 & 28.1 \\
$51-60$ & 12 & 37.5 \\
61-70 & 8 & 25 \\
\hline Pendidikan & & \\
SD & 1 & 3.1 \\
SMP & 1 & 3.1 \\
SMA & 19 & 59.4 \\
Diploma/ S1 & 11 & 34.4 \\
\hline Pekerjaan & & \\
IRT & 17 & 53.1 \\
wiraswasta & 8 & 25.0 \\
karyawan swasta & 4 & 12.5
\end{tabular}




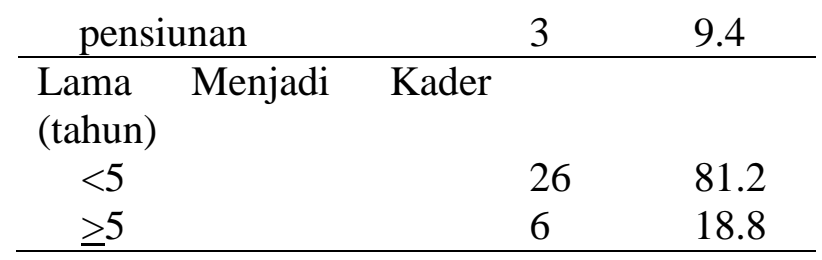

Tabel 3. Analisis Deskriptif Usia dan Lama Menjadi Kader

\begin{tabular}{lrrrrr}
\hline Karakteristik & $\mathrm{n}$ & \multicolumn{3}{c}{ Minimum Maximum Mean } & $\begin{array}{c}\text { Standar } \\
\text { Deviasi }\end{array}$ \\
\hline Usia & 31 & 25 & 69 & 53.00 & 10.14 \\
Lama Menjadi Kader & 32 & 1 & 5 & 2.78 & 1.36 \\
\hline
\end{tabular}

Dalam Tabel 4, nampak bahwa kader umumnya telah memiliki pengetahuan yang cukup baik tentang faktor risiko TB (domain 1) dan peran kader (domain 4). Setelah dilakukan post-test, terdapat peningkatan skor pada semua domain dan skor total.

Tabel 4. Skor Pengetahuan Kader

\begin{tabular}{clrrrrr}
\hline $\begin{array}{c}\text { Domai } \\
\mathbf{n}\end{array}$ & SKOR & N & $\begin{array}{c}\text { Minimu } \\
\mathbf{m}\end{array}$ & $\begin{array}{c}\text { Maximu } \\
\mathbf{m}\end{array}$ & Mean & $\begin{array}{c}\text { Std. } \\
\text { Deviation }\end{array}$ \\
\hline 1 & Faktor risiko TB & 32 & 3.00 & 6.00 & 5.69 & 0.74 \\
2 & Gejala TB-DM & 32 & 1.00 & 4.00 & 3.38 & 0.91 \\
3 & Bahaya TB-DM & 32 & 0.00 & 5.00 & 4.47 & 1.05 \\
4 & Peran Kader & 32 & 2.00 & 4.00 & 3.88 & 0.42 \\
& Pre-test Total & $\mathbf{3 2}$ & $\mathbf{1 2 . 0 0}$ & $\mathbf{1 9 . 0 0}$ & $\mathbf{1 7 . 4 1}$ & $\mathbf{2 . 1 4}$ \\
\hline 1 & Gejala TB & 32 & 5.00 & 6.00 & 5.94 & 0.26 \\
2 & Gejala TB-DM & 32 & 3.00 & 4.00 & 3.87 & 0.34 \\
3 & Bahaya TB-DM & 32 & 4.00 & 5.00 & 4.97 & 0.18 \\
4 & Peran Kader & 32 & 4.00 & 4.00 & 4.00 & 0.00 \\
& Post-test Total & $\mathbf{3 2}$ & $\mathbf{1 8 . 0 0}$ & $\mathbf{1 9 . 0 0}$ & $\mathbf{1 8 . 7 8}$ & $\mathbf{0 . 4 2}$ \\
\hline
\end{tabular}

Karena distribusi tidak normal $(\mathrm{p}=0.000)$, digunakan Wilcoxon's Signed Rank Test. Pada Tabel 5, tampak bahwa skor yang berbeda bermakna antara pre dan post-test adalah skor total, gejala TB-DM, dan bahaya TB-DM $(\mathrm{p}<0.05)$. Hal ini sesuai dengan dugaan bahwa umumnya kader telah memiliki pengetahuan yang baik tentang gejala TB secara umum dan upaya atau peran yang dapat mereka lakukan dalam pengendalian TB, tetapi belum memiliki pengetahuan cukup terkait TB-DM.

Tabel 5. Hasil Uji Wilcoxon's Signed Rank

\begin{tabular}{lc}
\hline \multicolumn{1}{c}{ Domain } & $\boldsymbol{p}$ \\
\hline Gejala TB & 0.066 \\
Gejala TB-DM & 0.005 \\
Bahaya TB-DM & 0.006 \\
Upaya Kader & 0.102 \\
Skor Total & 0.001 \\
\hline
\end{tabular}

Pengabdi juga melakukan observasi jalannya kegiatan dan menganalisis feedback dari mitra kegiatan, yaitu dokter puskesmas, peserta, dan panitia. Berdasarkan observasi selama kegiatan berlangsung, peserta tampak antusias mengikuti seluruh rangkaian acara, aktif bertanya, dan 
menjawab pertanyaan. Kegiatan juga bermanfaat dan dapat diterima serta dimungkinan untuk diadaptasi untuk kelompok masyarakat lainnya. Hal ini sesuai dengan yang dinyatakan informan-informan dalam pernyataan sebagai berikut.

"Alhamdulillah peserta antusias, dan insyaAllah materi bisa mereka pahami." (Informan

1, pengurus TB-HIV Care Kota Yogyakarta)

"Kegiatan upgrade pengetahuan untuk kader ini nanti bisa kita sesuaikan untuk kader di

puskesmas. Kami masih mencari waktu dan cara yang tepat karena masih pandemi. (informan 2, dokter Puskesmas)

\section{Pembahasan}

Topik komorbiditas TB-DM merupakan hal yang relatif baru di Indonesia meskipun kasus klinis yang telah ternotifikasi tidak sedikit. Pengabdian masyarakat tentang edukasi TB-DM pada kader ini merupakan yang pertama di Indonesia dan dilakukan dengan dengan pendekatan partisipatif petugas kesehatan dan pengelola kader. Upaya edukasi secara umum bermanfaat untuk meningkatkan pengetahuan peserta. Hal ini konsisten dengan hasil penelitian dan pengabdian masyarakat lain. Dalam hal ini, upaya-upaya pelatihan kader umumnya dapat meningkatkan pengetahuan mereka (Boy, 2015; Rizqi \& Fitriawan, 2020).

Selain presentasi materi, dalam pelatihan kali ini terdapat leaflet dan video animasi yang digunakan untuk menunjang materi yang disampaikan. Berbagai media alternatif dengan konsep visual atau audio-visual seperti umumnya diperlukan untuk merangsang pembelajaran, menarik perhatian, dan menciptakan suasana pembelajaran yang menyenangkan dan memotivasi audiens yang dituju untuk mengalami perilaku atau kegiatan baru (Scherf, 1994).

Berdasarkan hasil wawancara dan observasi, upaya edukasi ini tampak acceptable dan appropriate, baik bagi peserta, pengurus kader, maupun petugas puskesmas yang terlibat sebagai edukator. Agar dapat diterapkan, materi, media, dan cara penyampaian edukasi haruslah dapat diterima (acceptable). Hal tersebut meliputi indikator memuaskan dalam berbagai aspek inovasi. Hal ini meliputi konten, kredibilitas, kenyamanan, penyampaian, dan kompleksitasnya (Proctor et al., 2011). Selain itu, agar dapat diterapkan, materi haruslah dipersepsikan sesuai (appropriate), relevan, dan kompatibel untuk mengatasi masalah yang ada serta dianggap bermanfaat dan dapat diterapkan (Proctor et al., 2011).

Kegiatan edukasi kader yang dilakukan bersifat multi-faceted dengan menggunakan action research. Metode ini bermanfaat dalam meningkatkan peran serta, efektivitas, dan kesinambungan implementasi program/ berbagai intervensi kesehatan (Bennett, 2004; Jacobs, 2016).

\section{Simpulan}

Kegiatan edukasi TB-DM pada kader merupakan inisiasi awal peningkatan peran komunitas dalam kolaborasi pengendalian dan pelayanan TB-DM di Indonesia. Kegiatan ini acceptable dan appropriate untuk dilaksanakan. Selain itu, terdapat perbedaan bermakna tentang skor pengetahuan kader sebelum dan sesudah sesi edukasi dengan materi dan media edukasi yang diberikan.

Upaya pemberdayaan lebih lanjut sebaiknya dilakukan dengan durasi pengamatan lebih lama agar dapat menilai implementation outcome lebih optimal. Pelatihan pada kader dengan karakteristik lain juga diperlukan mengingat Indonesia memiliki beragam budaya dan kondisi sosiodemografis yang mungkin membutuhkan pendekatan spesifik.

\section{Ucapan Terima Kasih}

Terima kasih kami ucapkan kepada FKIK UMY sebagai penyandang dana kegiatan, Dinas Kesehatan Kota Yogyakarta dan Puskesmas Danurejan 1 yang telah mendukung acara, serta TBHIV Care 'Aisyiyah Yogyakarta atas partisipasi aktifnya. 


\section{Daftar Pustaka}

Bennett, M. (2004). A Review of the Literature on the Benefits and Drawbacks of Participatory Action Research. First Peoples Child and Family Review, 14(1), 109-122.

Boy, E. (2015). Efektifitas Pelatihan Kader Kesehatan dalam Penanganan Tuberkulosis di Wilayah Binaan. Jurnal Pendidikan Kedokteran Indonesia, 4(2), 83-89.

Coghlan, D., \& Brannick, T. (2005). Doing Action in Your Own Organization.

Harries, A. D., Kumar, A. M. V., Satyanarayana, S., Lin, Y., Zachariah, R., Lönnroth, K., \& Kapur, A. (2015). Diabetes mellitus and tuberculosis: programmatic management issues. The International Journal of Tuberculosis and Lung Disease, 19(8), 879-886.

Jacobs, S. D. (2016). The Use of Participatory Action Research within Education-Benefits to Stakeholders. World Journal of Education, 6(3), 48-55.

Kemenkes RI. (2015). Petunjuk Teknis Penemuan Pasien TB-DM di FKRTL. Kementerian Kesehatan RI. http://www.tbindonesia.or.id/tbident/uploads/2017/02/Buku-PetunjukTeknis-Penemuan-Pasien-TB-DM-Di-Fasilitas-Kesehatan-Rujukan-Tngkat-Lanjut.pdf

Kemenkes RI. (2018). Hasil Utama Riset Kesehatan Dasar (RISKESDAS). In Riset Kesehatan Dasar (Vol. 44, Issue 8). https://doi.org/10.1088/1751-8113/44/8/085201

Keputusan Menteri Indonesia Republik Indonesia Nomor HK.01.07/MENKES/755/2019 tentang Pedoman Nasional Pelayanan Kedokteran Tata Laksana Tuberkulosis, Kementerian Kesehatan Republik Indonesia 139 (2019).

Proctor, E., Silmere, H., Raghavan, R., Hovmand, P., Aarons, G., Bunger, A., Griffey, R., \& Hensley, M. (2011). Outcomes for implementation research: Conceptual distinctions, measurement challenges, and research agenda. Administration and Policy in Mental Health and Mental Health Services Research, 38(2), 65-76.

Rizqi, J., \& Fitriawan, A. S. (2020). Pelatihan dan pendampingan kader kesehatan tentang pengukurn kadar glukosa darah sebagai upaya deteksi dini diabetes mellitus. Jurnal Suaka Insan Mengabdi, 2(2), 47-54.

Scherf, K. (1994). Beyond the Brochure: Alternative Approach to Effective Health Communication. In Cultural Mapping as Cultural Inquiry.

Utarini, A. (2020). Tak Kenal Maka Tak Sayang: Penelitian Kualitatif dalam Pelayanan Kesehatan. Yogyakarta: Gadjah Mada University Press.

WHO. (2018). Global Tuberculosis Report 2018. In WHO. https://doi.org/10.1016/j.pharep.2017.02.021

World Health Organization. (2019). World health statistics 2019: monitoring health for the SDGs, sustainable development goals. In World Health Organization. https://doi.org/10.4324/9781315853178 